\title{
BMJ Open Nutrition and physical performance in older people-effects of marine protein hydrolysates to prevent decline in physical performance: a randomised controlled trial protocol
}

Linda Anette Kornstad Nygård, ${ }^{1}$ Ingunn Mundal, ${ }^{1}$ Lisbeth Dahl, ${ }^{2}$ Jūrate Šaltyte Benth, ${ }^{3,4}$ Anne Marie Mork Rokstad ${ }^{1,5}$

To cite: Nygård LAK, Mundal I, Dahl L, et al. Nutrition and physical performance in older people-effects of marine protein hydrolysates to prevent decline in physical performance: a randomised controlled trial protocol. BMJ Open 2018;8:e023845. doi:10.1136/ bmjopen-2018-023845

\section{- Prepublication history for} this paper is available online. To view these files, please visit the journal online (http://dx.doi. org/10.1136/bmjopen-2018023845).

Received 28 April 2018 Revised 26 August 2018 Accepted 31 August 2018

Check for updates

(C) Author(s) (or their employer(s)) 2018. Re-use permitted under CC BY-NC. No commercial re-use. See rights and permissions. Published by BMJ.

${ }^{1}$ Health and Social Science, Molde University College, Molde, Norway

${ }^{2}$ Food Security and Nutrition, Institute of Marine Research (IMR), Bergen, Norway ${ }^{3}$ Institute of Clinical Medicine, University of Oslo, Oslo, Norway ${ }^{4}$ Health Services Research Unit, Akershus University Hospital, Lørenskog, Norway

${ }^{5}$ Norwegian National Advisory Unit on Ageing and Health, Vestfold Hospital Trust, Tønsborg, Norway

Correspondence to Linda Anette Kornstad Nygård; linda.nygard@himolde.no

\section{ABSTRACT}

Introduction Age-related loss of muscle mass, muscle strength and muscle function (sarcopenia) leads to a decline in physical performance, loss of independence and reduced quality of life. Nutritional supplements may delay the progression of sarcopenia. The aim of this randomised, double-blinded controlled trial including 100 participants ( $\geq 65$ years) is to assess the effect of a marine protein hydrolysate (MPH) on sarcopenia-related outcomes like hand grip strength, physical performance or gait speed and to study the associations between physical performance and nutritional intake and status.

Method and analysis The intervention group $(n=50)$ will receive $3 \mathrm{~g}$ of MPH per day in 12 months. The control group $(n=50)$ receive placebo. Assessments of Short Physical Performance Battery (SPPB), hand grip strength, anthropometric measurements, nutritional status as measured by the Mini Nutritional Assessment, dietary intake, supplement use, biomarkers of protein nutrition and vitamin $D$, and health-related quality of life (EQ-5D), will be performed at baseline and after 6 and 12 months of intervention. Linear mixed models will be estimated to assess the effect of MPH on SPPB, hand grip strength and quality of life, as well as associations between physical performance and nutrition.

Ethics and dissemination The study has been approved by the Regional Committee in Ethics in Medical Research in Mid-Norway in September 2016 with the registration ID 2016/1152. The results will be actively disseminated through peer-reviewed journals, conference presentations, social media, broadcast media and print media.

Trial registration number NCT02890290.

\section{INTRODUCTION}

Age-related loss of muscle mass, muscle strength and muscle function (ie, sarcopenia) leads to a decline in physical performance, loss of independence and reduced quality of life. The elderly are vulnerable for low physical activity and periods of bed rest, and they experience more severe loss of lean tissue/ muscle mass than younger adults do. Their
Strengths and limitations of this study

- The study is designed as a randomised controlled trial, and the intervention is placebo controlled and double blinded.

- A strength of this study is the comprehensive data collection, with physical and anthropometric measures related to a thorough assessment of nutritional intake, nutritional status and view on nutrition.

- The intervention period for this study is 6-12 months, making the study appropriate for documenting potential preventive effects on age-related loss of muscle function or strength.

- A limitation of this study may be the anthropometric method used to assess muscle mass.

muscles have a reduced ability to synthesise muscle protein which leads to muscle wasting. This might be related to an anabolic signalling deficit and amino acid resistance in this population, as muscle protein synthesis (MPS) in response to the intake of amino acids is reduced in older people compared with younger populations. ${ }^{1}$

Sarcopenia (muscular atrophy) is a chronic condition characterised by age-related loss of muscle mass, muscle strength and/or muscle function $^{2}$; it can initiate disability and is related to the concept of frailty. ${ }^{3}$ Moreover, there is a correlation between sarcopenia and increased mortality. ${ }^{2}$ The prevalence of sarcopenia is substantial in most geriatric settings and ranges from $1 \%$ to $29 \%$ in community-dwelling populations and $14 \%$ to $33 \%$ in long-term care populations. ${ }^{4}$ Furthermore, it may be underdiagnosed and have multiple causes $^{56}$ and is also associated with insulin resistance and low-grade inflammation. ${ }^{7}$

Exercise, diet and nutritional interventions seem to have a preventive effect on the 
progression of sarcopenia. ${ }^{8}$ However, nutritional interventions are sparse and equivocal due to the low number of studies and their heterogeneous design. ${ }^{4} \mathrm{~A}$ recent meta-analysis concluded that the evidence for exercise and nutritional interventions in treating sarcopenia in older people is of low quality. ${ }^{10}$

Proteins and amino acids are among the nutrients suggested to counteract or delay sarcopenia, ${ }^{11}{ }^{12}$ and a case-control study of sarcopenic and non-sarcopenic older people in the UK found lower protein intake $(6 \%)$ among sarcopenic participants. ${ }^{13} \mathrm{~A}$ higher protein intake is recommended for older people, at least $1.0-1.2 \mathrm{~g}$ per $\mathrm{kg}$ of body weight daily to maintain muscle strength and function. ${ }^{11}$ There is also growing evidence that the distribution of protein during the day might be as important as total intake, and that there might be a protein threshold regarding how much protein should be eaten at each meal to stimulate MPS. ${ }^{12}{ }^{14}$ A dose-response study suggested that $20 \mathrm{~g}$ of whey protein was the optimal dose for young people, while a dose of $40 \mathrm{~g}$ had a more beneficial effect for the elderly. ${ }^{15}$ However, elderly persons often have poor appetites, reduced uptake of nutrients from food and difficulties exercising. Thus, specific nutrient supplementation might benefit this population as part of a multimodal approach. ${ }^{16}$

Novel findings from the Maastricht Sarcopenia Study, presented at the 2016 Sarcopenia Cachexia and Wasting Disease conference in Berlin, showed that reduced levels of branched-chain amino acids in the blood seem to be associated with sarcopenia in older people. ${ }^{17}$ Hence, they need a greater amount of leucine and other essential amino acids to stimulate MPS compared with younger people. Leucine supplements partially protected muscle mass and function during bed rest in middle-aged men, ${ }^{18}$ a protective effect that was not found in a study of young men. ${ }^{19}$

Marine proteins are leucine rich and well balanced in other essential amino acids. Furthermore, proteins from seafood may have properties different from those in meat. In a Norwegian intervention study using a crossover design, healthy volunteers consumed meals with similar compositions except for the protein source. ${ }^{20}$ The researchers found a decrease in risk factors for cardiovascular disease in the study group for which the protein source was fish. The diets were equal in terms of the distribution of carbohydrates, proteins and fat, and cod liver oil was added to the meat meals to balance the long-chained fatty acids in fish. This provides evidence that fish protein may have a health effect per se. Supplementation with $3 \mathrm{~g}$ fish protein (tablets) for 4 weeks had effects on body composition in overweight adults, including an increased percentage of body muscle and decreased percentage of body fat ${ }^{21}$

Protein hydrolysis, the cleavage of peptide bonds, results in smaller peptides that are easily digested and have greater resistance to gastric acid and heat. ${ }^{22}$ Hydrolysates of whey protein have been shown to stimulate MPS better than whole-protein soy and casein do, and this may be related to differences in absorption or small differences in leucine content. ${ }^{23}$ Hydrolysates of marine proteins have bioactive functions, and positive health effects have been noted in several areas. ${ }^{22}$ Nobile et al demonstrated that marine protein hydrolysate (MPH) had a positive effect on body composition in overweight adults in doses of 1.4 or $2.8 \mathrm{~g} .^{24}$

To our knowledge, no previous trials have tested MPH in community-dwelling elderly persons without additional training interventions.

The overall objective of this project is to study how nutritional status and dietary intake influence physical function in home-dwelling elderly persons.

This study aims to address the following hypotheses/ research questions:

1. Daily intake of $3 \mathrm{~g}$ MPH for 6-12 months prevents loss of physical performance as measured by the Short Physical Performance Battery (SPPB) compared with placebo.

2. Daily intake of $3 \mathrm{~g}$ MPH for 6-12 months prevents loss of muscle strength as measured by hand grip strength compared with placebo.

3. What are the associations between nutritional status, intake of protein and physical performance and hand grip strength in older people?

\section{DESIGN AND METHODS}

\section{Study design}

The study is a randomised controlled double-blinded trial. Comprehensive data collection will be used to examine the participants' nutritional status and physical function. Data will be collected at baseline and 6 and 12 months after the start of the intervention. Possible effects of the supplemented MPH will be assessed by examining differences between the intervention and placebo groups throughout the follow-up period.

\section{Recruitment}

The participants will be men and women 65 years old and older. Exclusion criteria include active cancer illness or progressive muscle illness (eg, multiple sclerosis or Lou Gehrig's disease), diabetes, kidney failure, short life expectancy $(<1$ year) and allergies to fish protein.

Participants will be recruited both through home care services and by advertising for volunteers. Health professionals in the municipal home care service will receive oral and written information about the intervention from the researcher and will be instructed to provide eligible participants with written information and an invitation to participate in the study. Recruiters will be further instructed to consider the elderly person's capacity to give informed consent to participate before extending an invitation. Besides, recruiters will keep a register and report the number of elderly persons who do not meet the inclusion criteria, and the age and gender of those not willing to participate. Moreover, posters and flyers will be distributed at senior centres and elsewhere, for 
volunteers to contact the researcher directly. Those who express their willingness to participate will receive a call from the researcher with additional information and the opportunity to ask questions before they decide whether to participate. If they decide to participate, a home visit is scheduled.

Recruitment will begin in one municipality and expand from there until 100 participants are included. All participants will be asked to sign a letter of consent at the first home visit. Participants will be recruited and allocated from October 2017 to August 2018, and the follow-up time will be 1 year.

We do not anticipate this project causing any harm or discomfort to the participants, and we will ensure that our participants participate in the study voluntarily. Participants will be given both oral and written information about the study twice before they provide their consent to participate. First, they will receive information from either posters/flyers or their home care nurse, and second, they will be offered the opportunity to ask the researcher questions directly before signing the written consent form. Furthermore, they will be informed about their right to withdraw from the study with no consequences at any time.

\section{Patient and public involvement}

The baseline assessment was administered to elderly persons during the development of the study design; however, the burden of the intervention was not assessed by elderly people. Results from the study will be disseminated to study participants through newsletters and open lectures.

\section{Assessments}

The data collection will be completed in participants' homes at baseline and after 6 and 12 months, and includes SPPB and hand grip strength, anthropometric measurements, a five level version of the EuroQol five dimension (EQ-5D-5L) questionnaire, a short Food Frequency Questionnaire (FFQ), and a 24-hour food-recall interview. The researcher will complete the questionnaires based on a structured interview with each participant. Furthermore, the participants will be instructed to visit their general practitioner for blood sampling. The researcher will perform all other assessments.

\section{Main outcome: SPPB}

Muscle performance will be measured with the SPPB, a test battery developed originally for the Established Populations for Epidemiologic Studies of the Elderly and translated into Norwegian in 2013 by Bergh $e t a l^{25}$ The test battery includes standing balance, walking speed and repeated chair rise. Each of the three domain scores range from 0 to 4 points, yielding an integer score ranging from 0 to 12 points. A higher score indicates a higher level of functioning, and a change of one unit is considered a clinically meaningful change ${ }^{26}$ A systematic review of instruments assessing performance-based physical function in older community-dwelling persons concluded that the SPPB can be highly recommended in terms of validity, reliability and responsiveness. ${ }^{27}$ The SPPB complements self-reported disability and may predict mortality and nursing home admission even at the high end of the functional spectrum. ${ }^{28}$ Gait speed may be calculated as metres per second from the $4 \mathrm{~m}$ walking test included in SPPB. Gait speed alone is nearly as useful as the full battery for predicting disability. However, the assessment of balance and chair-rise ability is clinically important. ${ }^{29}$

\section{Secondary outcome: hand grip strength}

Hand grip strength is measured to the nearest $0.1 \mathrm{~kg}$ using the Jamar Plus +digital hand dynamometer. We will record three trials from each hand, with participants in a sitting position and the arm at a $90^{\circ}$ angle, as described in Roberts et $a l^{30}$ The maximum of these values will be used for analyses. ${ }^{31}$ Grip strength is a useful and simple measure of muscle strength. It correlates with leg strength, is a clinical marker of poor mobility and is considered a better predictor of clinical outcomes than low muscle mass. ${ }^{2}$ Cut-off scores are set to $30 \mathrm{~kg}$ and $20 \mathrm{~kg}$ for men and women, respectively. ${ }^{2}$ However, Dodds $e t$ al provide normative data with centile values for grip strength across the life course. ${ }^{31}$

\section{Secondary outcome: health-related quality of life}

Health-related quality of life (HRQOL) will be assessed by the EQ-5D-5L questionnaire. ${ }^{32}$ The EQ-5D-5L consists of the EQ-5D descriptive system and the EQVisual Analogue Scale (EQ VAS). The descriptive system comprises the following five dimensions: mobility, self-care, usual activities, pain/discomfort and anxiety/depression. Each dimension has five levels: no problems, slight problems, moderate problems, severe problems and extreme problems. The VAS assesses subjective health on a $0-100$ scale, with 0 representing the worst possible and 100 the best possible health. EQ-5D-5L has been validated in a diverse population in several countries, including multiple patient groups with chronic conditions. ${ }^{33}$

\section{Explanatory variables}

The age, gender, physical activity and educational level of the participants may influence both nutritional status and physical function and are regarded as explanatory factors. Moreover, we believe that living alone or with a partner may influence dietary intake, as social relations affect food habits. Weight, body mass index (BMI) and muscle mass are also regarded as explanatory factors. Body mass is recorded in light clothing to the nearest $0.1 \mathrm{~kg}$ using a digital scale (Seca 803 ) and height and leg circumference with a tape measure (Seca 201). Muscle mass will be estimated from calf circumference and weight, using equation $1 .^{34}$

$$
\begin{aligned}
M M(\mathrm{~kg})= & -0.543+(0.162 * \text { body mass })+ \\
& (0.151 * \text { calf circumference })
\end{aligned}
$$

\section{Nutritional status}

An assessment of nutritional status will be made by the nutritional screening and assessment tool, Mini 
Nutritional Assessment (MNA), and biomarkers in serum/blood. The MNA tool was developed by Nestlé Nutrition Institute and is commonly used worldwide. ${ }^{35}$ The full version comprises 18 items contributing to a sum score of $0-30$ points. The reliability and validity of the full MNA is well established across care settings and has a sensitivity of $96 \%$ and specificity of $98 \%$ compared with clinical status. The specificity is lower compared with other nutritional assessment methods; however, sensitivity remains strong. ${ }^{35}$ The MNA is recommended by the Norwegian Directorate of Health to assess nutritional status in elderly persons. ${ }^{36}$

Non-fasting blood samples will be collected for the determination of albumin, prealbumin, retinol-binding protein, glycated haemoglobin A1c and vitamin D (25-hydroxy vitamin D) as well as markers of inflammation, that is, $\mathrm{C}$ reactive protein and creatine kinase. The blood samples will be analysed in hospital laboratories (standard routine analyses). Visceral proteins (albumin, prealbumin and retinol-binding protein) are commonly used as biomarkers of nutritional protein status and regarded as useful indices in the assessment of malnutrition among the elderly. ${ }^{37}$ Vitamin D is important for maintaining bone health, and its deficiency may predict hip fracture. ${ }^{38}$ A supplement of whey protein enriched with vitamin D improved muscle mass in sarcopenic older adults. ${ }^{16}$ Hence, the analyses in this project should control for vitamin D status.

\section{Nutritional intake}

Daily energy (kcal/day) and protein intake (g/day) will be estimated using a 24-hour recall of food intake, following the protocol and method described in the Newcastle $85+$ study (freely available at the website for the Medical Research Council in the UK) ${ }^{39}$ To adapt the method to Norwegian participants, we use the food-portion illustrated booklet (with a corresponding list of weights) from the Norwegian study 'Ungkost 2000' ${ }^{40}$

The multiple-pass recall (MPR) method can accurately assess intakes regardless of the subjects'BMI. ${ }^{41}{ }^{42}$ As this study recruits participants without an upper age limit, a dietary assessment method also applicable for the very old was chosen. The 24-hour food recall was considered the preferred method for dietary assessment among the oldest old (85+years), based on both performance and practical applicability in this age group. ${ }^{43}$ The estimated daily energy, protein and other nutrients intakes are better aligned with the corresponding means from weighed dietary intakes in the UK National Diet and Nutrition Survey, compared with the FFQ. ${ }^{43}$

Both MPR and FFQ measured higher intakes than the weighed intake in the $85+$ study. This might be due to an overestimation of intake in the two retrospective methods, but as prospective methods tend to affect food intake, ${ }^{44}$ the retrospective methods still might be more representative of true intake. Seafood intake will be assessed by a validated $\mathrm{FFQ}^{45}$

\section{Views on nutrition and need for nutritional support}

A questionnaire developed for this study, asks participants to agree or disagree with statements about food and nutrition, for example, 'I prefer to eat alone' or 'Food doesn't taste like it used to'. Moreover, we ask the participants whether they receive help preparing and eating their meals, and who they prefer to consult for nutritional advice. These data will be presented descriptively in relation to nutritional status and intake.

\section{Intervention}

The participants will take the supplement in tablet form and will be instructed to take five tablets two times a day, preferably in relation to breakfast and the evening meal. Each tablet contains $300 \mathrm{mg}$ of MPH (Nx6.25), which yields a total dose of $3 \mathrm{~g}$ per day $(1.5 \mathrm{~g}$ morning and $1.5 \mathrm{~g}$ evening) in accordance with other studies, ${ }^{21}{ }^{24}$ The tablets are produced by Flexipharma AS and based on the marine peptide compound $565952 \mathrm{P}$ from Firmenich Bjørge Biomarin AS. Placebo tablets are produced based on gum arabic. The marine peptide compound is manufactured through the hydrolysis of fresh or fresh-frozen Atlantic Cod fillet (Gadus morhua) using industrial food approved non-GMO proteolytic enzymes and added maltodextrin from corn to prevent the odour and taste of fish. Hydrolysis is conducted using equipment and procedures according to regulations provided by the Norwegian food authorities. Marine peptides are approved as a food ingredient in Norway according to EU regulations.

\section{Compliance}

Compliance will be assessed by calculating the percentage of supplement taken. The participants will be asked to keep a record of their supplement intake, and questions on compliance will be asked at the 6 and 12 months follow-ups.

\section{Randomisation and blinding}

The participants will be given project identification numbers, which will be randomised into two groups. Block randomisation will be performed, with blocks based on the baseline score of the SPPB test. The main researcher (LAKN) enrols participants and forwards identification numbers and block information to the statistician (Jك̌B), who performs the randomisation to either group A or group B. The group A or B allocation will be sent to a person not connected to the project, who will prepare supplement and placebo boxes by marking them with an identification number only. Trial participants, care providers, outcome assessor and data analysts are blinded for the intervention, and the intervention groups will not be revealed until all data have been analysed.

\section{Sample size and statistical power calculation}

The main outcome of this study is physical performance, as measured by the SPPB on a 12-point scale. In accordance with previous studies, a clinically meaningful change in score on this scale is reported to be $0.4-1.5$ points. ${ }^{26}$ Based on this study, we assume that the mean 
SPPB score at inclusion is 7.52 in both groups. We also assume that the intervention group maintains a stable SPPB score throughout the study period, while the score decreases by an average 0.9 points in the control group. In addition, we assume that the SD after the intervention period is 1.42 in both groups. A sample size of 41 participants is required in each group to detect a statistically significant mean difference of 0.9 points at a significance level of $5 \%$ and with a power of $80 \%$ using a two-sided independent samples t-test. As the participants are older, we expect a drop-out/missing frequency of $20 \%$; therefore, we aim to include 50 participants in each group.

\section{Statistical analyses}

The demographic and clinical characteristics of the participants in each group will be described as means and SDs or frequencies and percentages, as appropriate. A linear mixed model will be estimated to assess the effect of MPH on the primary outcome, the SPPB, in the intervention and placebo groups throughout the 12-month follow-up. The model will include fixed effects for time components up to the second order, group allocation and the interaction between the two. Random effects for participants will be included to correctly adjust estimates for possible intraparticipant correlations due to repeated measurements for each participant. Random slopes for time component will be considered. A significant interaction between time and group allocation would imply differences in SPPB scores between the groups throughout the follow-up. Pairwise comparisons will be conducted by deriving individual time point contrasts within each group with corresponding $95 \%$ CIs and $\mathrm{p}$ values. The results will be further adjusted for a number of covariates (age, gender, education, physical activity, living status, seafood intake, nutritional status, vitamin D level and energy intake). Secondary outcomes, hand grip strength $(\mathrm{kg})$, HRQOL measured by the EQ-5D-5L and health as measured by the VAS will be assessed by similar models. The results will be tabulated and presented graphically to facilitate their interpretation.

To assess whether nutrition is associated with SPPB, HRQOL and hand grip strength at baseline, linear mixed models will be estimated. Nutrition will be the main fixed effect in all models. The models will be further adjusted for a number of other important variables including age, gender, living status, seafood intake, vitamin D level, protein nutrition markers, habitual protein intake, protein intake and energy intake.

As participants will be recruited from different municipalities, within-municipality correlations might be present in the data. To correctly adjust for such correlations, random effects for municipality will be included in all models. The multiple models will be reduced by applying Akaike's information criterion. Model assumptions will be assessed as appropriate and, in the event of violations, necessary adjustments implemented. The statistical analyses will be performed using SPSS V.24 and SAS V.9.4. Results with $\mathrm{p}$ values below 0.05 will be considered statistically significant. The intention-to-treat sample will be used in statistical analysis, and per-protocol analysis will be performed if relevant.

\section{Preregistration}

The trial is preregistered at http://www.clinicaltrials.gov.

\section{DISCUSSION}

The main purpose of this study is to examine the effects of MPH on physical performance in a population of older people. The double-blinded randomised controlled design is considered solid and sound for answering the main research question. Furthermore, this project provides important data on nutritional status and intake in this population. To gain a deeper understanding of the results of the randomised controlled trial, additional questions are included to provide a descriptive analysis on nutrition and factors influencing the nutritional status of older people.

The population of interest is older people. The participants are recruited either by invitation from the home care service or recruited from advertisements in local media, senior centres and suchlike. People with moderate or severe cognitive impairment, which can be considered to interfere with their capacity to give written informed consent, will not be approached to participate in the study, and this represents a limitation. However, we consider the recruitment procedure to provide a selection of participants who are potentially representative of the prefrail segment of the elderly population and thereby the target population for the intervention. Frailty partially overlaps the generally accepted concept of being 'old and weak', but it is not synonymous with comorbidity or disability; comorbidity is rather a risk factor for frailty, and disability can be an outcome of frailty. ${ }^{46}$ Fried provided a definition of frailty as a clinical syndrome in which three or more of the following criteria are present: unintentional weight loss, self-reported exhaustion, weakness (grip strength), slow walking speed and low physical activity. ${ }^{46}$ Later, these key indicators of frailty were discussed, and concerns were raised about the value of self-reported exhaustion and muscle weakness. However, slow gait speed, low physical activity, weight loss and cognitive impairment are still regarded as strong indicators of frailty. ${ }^{47}$ All of these factors may also reflect poor nutritional status, and additional studies on associations between nutrition and frailty are needed to address the challenges of frailty in old age. This study will focus on the sarcopenia-related indicators of frailty in elderly persons and the possibility of preventing sarcopenia and frailty through nutritional intervention.

A strength of this study is its comprehensive data collection. To the best of our knowledge, no previous study of physical performance in the elderly includes a thorough assessment of the participants' nutritional intake and status as this study does. Documentation regarding nutrition in home-dwelling elderly persons is sparse, 
although a prevalence study of 340 home-dwelling older persons receiving home care services in Oslo, Norway, reported that $46 \%$ were categorised as being or at risk of being, malnourished. ${ }^{48}$ Malnutrition among the elderly population is a serious concern, and at the University of Oslo, the cost-effectiveness of preventing malnutrition compared with treating it has been estimated at a savings of Kr800 million (ca. $€ 86$ million). ${ }^{49}$ In the case of insufficient intake of calories (negative energy balance), dietary proteins are used for energy utilisation rather than muscle protein synthesis. ${ }^{50}$ General malnutrition may, therefore, hasten the development of sarcopenia despite protein supplements. Thus, it is necessary to control for both general nutrition and protein nutrition status when assessing the effects of protein supplements on the development of sarcopenia.

Interventions designed to counteract age-related sarcopenia and help older people to maintain physical functioning are needed to meet the challenges of the increasing life span. As the average life span in Norway now exceeds 80 years, we aim to delay the need for help and care, from a socioeconomic perspective and to increase the quality of the additional years of life. We know that exercise and nutrition are important factors in preventing muscle loss. ${ }^{8}$ However, when we are the most vulnerable for muscle loss, for example, during bed rest after injury or illness, both appetite and the ability to exercise are reduced. Thus, the use of food supplementation to maintain muscle health in these situations will highly benefit an ageing population.

Dietary protein intake should be distributed over several meals, as there seems to be a protein threshold for the onset of MPS between $20 \mathrm{~g}$ and $40 \mathrm{~g}$ of protein per meal. ${ }^{81215}$ MPH or fish protein could stimulate MPS at lower doses of 1.4-6.0 g. ${ }^{2124}$ As muscle atrophy appears to happen rapidly after disuse/bed rest, ${ }^{18}$ stimulating MPS is of importance in situations of low activity and poor protein nutrition. A strength of this study is that the MPH supplement is to be taken in relation to breakfast and the evening meal, not dinner. This will provide a more evenly distributed protein intake/stimulation of MPS. To the best of our knowledge, there are no previous studies of distribution of protein intake in Norway. However, the lunchtime meal will typically contain less protein than in countries like the USA, and we believe that protein intake is less distributed than reported in the National Health and Nutrition Examination Survey (NHANES) study in the USA. ${ }^{12}$

A limitation of our study may be the anthropometric method used to assess muscle mass. According to the European Working Group on Sarcopenia in Older People (EWGSOP) consensus on the definition of sarcopenia, both muscle mass and muscle function (strength and performance) need to be assessed to identify sarcopenia. ${ }^{2}$ The EWGSOP recommends anthropometric measurements of muscle mass for clinical use only, as there are few studies validating anthropometric measurements in the elderly population, and they are vulnerable to errors.
However, in the present study, we use an inexpensive measurement that is easy to perform in the participants' homes. Hence, muscle mass is estimated from calf circumference and weight, with the equation for the estimation of muscle mass described by Santana. ${ }^{34}$ In multiple regression analysis of anthropometric measures in elderly women, body mass and calf circumference estimated muscle mass (measured by Dual-energy X-ray absorptiometry (DXA)) adequately (r 0.81 ), but it has not been validated and is tested only in women. Anthropometric estimation of muscle mass is considered vulnerable to error. $^{2}$ However, some studies argue for the use of calf circumference alone as a marker of sarcopenia in older adults. ${ }^{51}$ We have chosen physical function (SPPB) as our primary outcome, as there is growing evidence that loss of strength is a more consistent risk for disability and death than is loss of muscle mass. ${ }^{52}$

The project will have potential benefits for the target population. Increased knowledge of nutritional status and protein intake among this population group may facilitate nutritional interventions to prevent loss of physical function, potentially leading to increased independence and delayed need for residential institution. The results of this study may also be transferable to other populations with conditions where muscle atrophy is a concern, for example, inactivity after injuries, bed rest after surgery or in intensive care units.

Acknowledgements We wish to thank professor Emeritus Einar Lied and dr. Dag Arne Lihaug Hoff for their support and advice on practical issues in planning the study.

Contributors LAKN is responsible for the study. LAKN, AMMR, LD and IM developed the study design. JŠB planned and will perform the statistical analyses. LAKN drafted the manuscript, and AMMR, IM, LD and JŠB took part in the writing process. All authors have read and approved the final version of the manuscript.

Funding The project is funded by a general $\mathrm{PhD}$ grant from Molde University College. Blood analyses are funded by The Research Council of Norway, Programme for Regional R\&D and Innovation (VRI). The intervention is funded by Firmenich Bjørge Biomarin AS, which provided the marine protein hydrolysate supplement and placebo preparation.

Competing interests None declared.

Patient consent Not required.

Ethics approval The study will be conducted in accordance with the Declaration of Helsinki and was approved by the Regional Committee on Ethics in Medical Research in Mid-Norway in September 2016 with the registration ID 2016/1152.

Provenance and peer review Not commissioned; externally peer reviewed.

Open access This is an open access article distributed in accordance with the Creative Commons Attribution Non Commercial (CC BY-NC 4.0) license, which permits others to distribute, remix, adapt, build upon this work non-commercially, and license their derivative works on different terms, provided the original work is properly cited, appropriate credit is given, any changes made indicated, and the use is non-commercial. See: http://creativecommons.org/licenses/by-nc/4.0/.

\section{REFERENCES}

1. Cuthbertson D, Smith K, Babraj J, et al. Anabolic signaling deficits underlie amino acid resistance of wasting, aging muscle. Faseb $J$ 2005;19:422-4.

2. Cruz-Jentoft AJ, Baeyens JP, Bauer JM, et al. Sarcopenia: European consensus on definition and diagnosis: report of the european Working Group on Sarcopenia in older people. Age Ageing 2010;39:412-23. 
3. Mijnarends DM, Schols JM, Meijers JM, et al. Instruments to assess sarcopenia and physical frailty in older people living in a community (care) setting: similarities and discrepancies. J Am Med Dir Assoc 2015;16:301-8.

4. Cruz-Jentoft AJ, Landi F, Schneider SM, et al. Prevalence of and interventions for sarcopenia in ageing adults: a systematic review. Report of the International Sarcopenia Initiative (EWGSOP and IWGS). Age Ageing 2014;43:748-59.

5. Shils ME, Shike M. Modern nutrition in health and disease. 10th edn: Lippincott Williams \& Wilkins, 2006.

6. Fielding RA, Vellas B, Evans WJ, et al. Sarcopenia: an undiagnosed condition in older adults. Current consensus definition: prevalence, etiology, and consequences. International working group on sarcopenia. J Am Med Dir Assoc 2011;12:249-56.

7. Batsis JA, Buscemi S. In: Croniger DC, ed. Sarcopenia, sarcopenic obesity and insulin resistance, in medical complications of type: InTech, 2011.

8. Breen L, Phillips SM. Skeletal muscle protein metabolism in the elderly: Interventions to counteract the 'anabolic resistance' of ageing. Nutr Metab 2011;8:68.

9. Witard OC, McGlory C, Hamilton DL, et al. Growing older with health and vitality: a nexus of physical activity, exercise and nutrition. Biogerontology 2016;17:529-46.

10. Yoshimura Y, Wakabayashi H, Yamada M, et al. Interventions for treating Sarcopenia: a systematic review and meta-analysis of randomized controlled studies. J Am Med Dir Assoc 2017;18:553. e1-553.e16.

11. Deutz NE, Bauer JM, Barazzoni R, et al. Protein intake and exercise for optimal muscle function with aging: recommendations from the ESPEN Expert Group. Clin Nutr 2014;33:929-36.

12. Arentson-Lantz E, Clairmont S, Paddon-Jones D, et al. Protein: a nutrient in focus. Appl Physiol Nutr Metab 2015;40:755-61.

13. Verlaan S, Aspray TJ, Bauer JM, et al. Nutritional status, body composition, and quality of life in community-dwelling sarcopenic and non-sarcopenic older adults: A case-control study. Clin Nutr 2017;36:267-74

14. Bollwein J, Diekmann R, Kaiser MJ, et al. Distribution but not amount of protein intake is associated with frailty: a cross-sectional investigation in the region of Nürnberg. Nutr $J$ 2013;12:109.

15. Yang Y, Breen L, Burd NA, et al. Resistance exercise enhances myofibrillar protein synthesis with graded intakes of whey protein in older men. Br J Nutr 2012;108:1780-8.

16. Bauer JM, Verlaan S, Bautmans I, et al. Effects of a vitamin D and leucine-enriched whey protein nutritional supplement on measures of sarcopenia in older adults, the PROVIDE study: a randomized, double-blind, placebo-controlled trial. J Am Med Dir Assoc 2015; $16: 740-7$

17. Ter Borg S. Abstract 1-11 and 6-06 in Abstracts of the 9(th) International Conference on Cachexia, Sarcopenia and Muscle Wasting, Berlin, Germany, 10-11 December 2016 (part 1). Journal of Cachexia, Sarcopenia and Muscle 2016;7:626-62.

18. English KL, Mettler JA, Ellison JB, et al. Leucine partially protects muscle mass and function during bed rest in middle-aged adults. Am $J$ Clin Nutr 2016;103:465-73.

19. Backx EMP, Horstman AMH, Marzuca-Nassr GN, et al. Leucine Supplementation does not attenuate skeletal muscle loss during leg immobilization in healthy, young men. Nutrients 2018;10:635.

20. Aadland EK, Lavigne C, Graff IE, et al. Lean-seafood intake reduces cardiovascular lipid risk factors in healthy subjects: results from a randomized controlled trial with a crossover design. Am J Clin Nutr 2015;102:582-92.

21. Vikøren LA, Nygård $\mathrm{OK}$, Lied $\mathrm{E}$, et al. A randomised study on the effects of fish protein supplement on glucose tolerance, lipids and body composition in overweight adults. Br J Nutr 2013;109:648-57.

22. Vijaykrishnaraj M, Prabhasankar P. Marine protein hydrolysates: their present and future perspectives in food chemistry - a review. RSC Adv 2015:5:34864-77.

23. Tang JE, Moore DR, Kujbida GW, et al. Ingestion of whey hydrolysate, casein, or soy protein isolate: effects on mixed muscle protein synthesis at rest and following resistance exercise in young men. J Appl Physiol 2009;107:987-92.

24. Nobile V, Duclos E, Michelotti A, et al. Supplementation with a fish protein hydrolysate (Micromesistius poutassou): effects on body weight, body composition, and CCK/GLP-1 secretion. Food Nutr Res 2016;60:29857.

25. Bergh S, Lyshol H, Selbæk G, et al, 2013. Short Physical Performance Battery (SPPB), Norwegian. https://stolav.no/ Publishinglmages/Sider/Bevegelsesvansker-og-fall-hos-eldre/ SPPB\%20Norsk\%20versjon\%2006.05.13.pdf
26. Kwon S, Perera S, Pahor M, et al. What is a meaningful change in physical performance? Findings from a clinical trial in older adults (the LIFE-P study). J Nutr Health Aging 2009;13:538-44.

27. Freiberger E, de Vreede P, Schoene D, et al. Performance-based physical function in older community-dwelling persons: a systematic review of instruments. Age Ageing 2012;41:712-21.

28. Guralnik JM, Simonsick EM, Ferrucci L, et al. A short physical performance battery assessing lower extremity function: association with self-reported disability and prediction of mortality and nursing home admission. J Gerontol 1994;49:M85-M94.

29. Guralnik JM, Ferrucci L, Pieper CF, et al. Lower extremity function and subsequent disability: consistency across studies, predictive models, and value of gait speed alone compared with the short physical performance battery. J Gerontol A Biol Sci Med Sci 2000;55:M221-M231.

30. Roberts $\mathrm{HC}$, Denison $\mathrm{HJ}$, Martin $\mathrm{HJ}$, et al. A review of the measurement of grip strength in clinical and epidemiological studies: towards a standardised approach. Age Ageing 2011;40:423-9.

31. Dodds RM, Syddall HE, Cooper R, et al. Grip strength across the life course: normative data from twelve British studies. PLoS One 2014:9:e113637.

32. EuroQol. EQ-5D. http://www.euroqol.org/home.html

33. Janssen MF, Pickard AS, Golicki D, et al. Measurement properties of the EQ-5D-5L compared to the EQ-5D-3L across eight patient groups: a multi-country study. Qual Life Res 2013;22:1717-27.

34. Santana FdS, et al. Anthropometric parameters as predictors of muscle mass in elderly women/Parametros antropometricos como preditores da massa muscular em mulheres idosas. texto en ingles). Motricidade 2015;11:107.

35. Guigoz $\mathrm{Y}$. The mini nutritional assessment (mna) review of the literature-what does it tell us? J Nutr Health Aging 2006;10:466-85. discussion 485-7.

36. Guttormsen AB, Avdeling H. Nasjonale faglige retningslinjer for forebygging og behandling av underernaering. Oslo: Helsedirektoratet, Avdeling ernaering, 2009.

37. Sergi G, Coin A, Enzi G, et al. Role of visceral proteins in detecting malnutrition in the elderly. Eur J Clin Nutr 2006;60:203-9.

38. Holvik K, Ahmed LA, Forsmo S, et al. Low serum levels of 25-hydroxyvitamin D predict hip fracture in the elderly: a NOREPOS study. J Clin Endocrinol Metab 2013;98:3341-50.

39. Medical Research Council. DAPA measurement toolkit. http://dapatoolkit.mrc.ac.uk/index.php

40. Øverby NC, Frost Andersen L. Ungkost-2000: landsomfattende kostholdsunders?kelse blant elever i 4. - og 8. klasse i Norge. Oslo: Sosial- og helsedirektoratet, 2002.

41. Conway JM, Ingwersen LA, Vinyard BT, et al. Effectiveness of the US Department of Agriculture 5-step multiple-pass method in assessing food intake in obese and nonobese women. Am J Clin Nutr 2003;77:1171-8.

42. Conway JM, Ingwersen LA, Moshfegh AJ. Accuracy of dietary recall using the USDA five-step multiple-pass method in men: an observational validation study. J Am Diet Assoc 2004;104:595-603.

43. Adamson AJ, Collerton J, Davies K, et al. Nutrition in advanced age: dietary assessment in the Newcastle 85+ study. Eur J Clin Nutr 2009;63(Suppl 1):S6-S18.

44. Livingstone MB, Prentice AM, Strain JJ, et al. Accuracy of weighed dietary records in studies of diet and health. BMJ 1990;300:708-12.

45. Dahl L, Mæland CA, Bjørkkjær T. A short food frequency questionnaire to assess intake of seafood and $n-3$ supplements: validation with biomarkers. Nutr J 2011;10:127

46. Fried LP, Tangen CM, Walston J, et al. Frailty in older adults: evidence for a phenotype. J Gerontol A Biol Sci Med Sci 2001;56:M146-M157.

47. Rothman MD, Leo-Summers L, Gill TM. Prognostic significance of potential frailty criteria. J Am Geriatr Soc 2008;56:2211-6.

48. Sørbye LW. Hjemmetjenester til eldre - i Bærum og Ullern. Sammenlignende data fra AdHOC studiet. 2003, Diakonhjemmet H?gskole.

49. Juul $\mathrm{H}$. Forebygging og behandling av underernæring - oppgave kostnad nytte analyse, in Department of Health Management and Health Economics. Oslo: University of Oslo, 2010.

50. Sortland K, Steensæth Y, Gjerstad R. Ernæring - mer enn mat og drikke. 4. utg. ed. Bergen: Fagbokforl, 2011.

51. Kawakami R, Murakami H, Sanada K, et al. Calf circumference as a surrogate marker of muscle mass for diagnosing sarcopenia in Japanese men and women. Geriatr Gerontol Int 2015;15:969-76.

52. Mitchell WK, Williams J, Atherton P, et al. Sarcopenia, dynapenia, and the impact of advancing age on human skeletal muscle size and strength; a quantitative review. Front Physiol 2012;3:260. 